inhaler was used with carbolate of iodine. In a very few days a marked improvement set in, the swelling of the leg was almost gone, the lung symptoms were decidedly better, and the fetor less; some broken down lung tissue was expectorated, the murmur at the apex still persisting. He went on steadily improving, and in about fourteen days was almost well. There was still some cough and expectoration, but no fetor. The cardiac murmur was softer in character. Before the end of August he was able to get out; cough gone, and the heart-sounds quite normal. I saw him a year after a perfect picture of health. The lung sounds were perfect, and the heart quite normal.

That this was a case of ulcerative endocarditis I have no doubt now, but at that time there was not much known on the subject by the ordinary general practitioner. Both Dr. Stovin and myself attributed his recovery to the inhalations, and, I think, rightly so, as amendment in all the symptoms began almost directly after using the inhaler.

In the December following this, Dr. Julius Pollock related a case of ulcerative endocarditis with pyæmic symptoms, ${ }^{3} \mathrm{re}-$ sulting in death on the fifteenth day. He says: "The treatment of ulcerative endocarditis with pyæmia is most unsatisfactory; none of the ordinary remedies had any real effect, nor did large doses of alcohol sensibly improve matters. I wish now I had tried the inhalation of carbolic acid or carbolate of iodine, and I would suggest giving such a line of treatment a fair trial in any case of the kind, especially where the lungs appear to be much affected." The case, I may say, was watched attentively throughout by Dr. Stovin (now of Stratford) and myself. I am sorry my notes are defective, but $I$ think the main points and course of the case are correctly indicated. I have recently submitted them to Dr. Stovin for his verification.

In my recent case, though the inhalations were begun on the third day, I am afraid they were practically useless until the seventh day, when the oro-nasal inhaler was substituted. This was used throughout the illness for ten minutes at a time, about ten or twelve times in the twentyfour hours. I cannot help feeling that the gradual decline of the most urgent symptoms was due to the presence of the antiseptic in the blood, checking the growth and reproduction of the microbes, if not destroying them. The second indication in the treatment of my recent case was to keep up the failing power, and especially to combat the cardiac depression. Fortunately, nourishment was taken fairly well throughout (administered often), and consisted of strong broths, beef-tea, jellies, milk, eggs, \&c. Stimulants were givenfreely when absolutely required. Digitalis, though often indicated, was given with caution, fearing to excite sickness or nausea ; the sphygmograph was specially useful in giving the indication for it and recording its effects. During the most anxious part of the illness I was fortunate in having the co-operation and assistance of the young lady's brother, a very intelligent senior medical student, who watched the case most carefully, and to whom I am indebted for the minute records of the temperature. As he often heard the cardiac murmur curing the illness, he tells me he auscultated the heart recently, and that the sounds seemed to him quite right; he could detect no murmur. This I can verify, as I saw my patient on March 26th; she was then able to walk a mile without fatigue. The heart sounds were normal and the lungs sound.

\section{CASE OF ACUTE RHEUMATISM WITH HYPERPYREXIA.}

\section{BY ARTHUR J. DALTON, L.R.C.P. LOND., M.R.C.S.}

I READ with much interest Dr. Taylor's case of rheumatic hyperpyrexia in THE LANCET; and having had a very similar one lately in private, with even a higher temperature-viz., $108 \cdot 6^{\circ}$ in the axilla,-I venture to publish a few particulars of it.

Miss S-, aged twenty-four, never had rheumatism before, but her father, mother, and one sister had suffered from it on several occasions. On Dec. 31st the patient was seized with pains in the joints, which shortly became swollen and hot. On the fourth day she had a little pleurisy on the left side, with a good deal of pain. The temperature was never rery high. On January 6 th the pain in the joints disappeared, and an erythematous rash appeared over the body. The temperature now began to rise, and on the morning of Jan. 7 th was $103^{\circ}$. Up to this date I had only seen the patient once, my partner, Mr. F. M. Miller, having been in attendance. In the afternoon of the same day, at 3.50 P.M., they sent round in a great hurry, and, Mr. Miller being out, I went at once, to find the patient violently delirious, erythematous rash covering the body, pulse very feeble and not to be counted, and the temperature in the axilla $108 \cdot 6^{\circ}$. I immediateiy ordered half an ounce of brandy with a little milk, which was given by the mouth with great difficulty. The patient was then stripped, and a sheet wrung out with ice-cold water applied to the chest and abdomen; also several lumps of ice, four or five in number, were placed outside the sheet. The patient was so violently delirious that it took three people to hold the ice on and keep her in bed. The sheet was replaced by another at short intervals and fresh ice applied, - 4.5 P.M.: The brandy and milk, with a quantity of milk previously taken, was vomited, also a good deal of phlegm. 4.15 P.M.: Temperature $107^{\circ} 6^{\circ}$; pulse $160 .-4.45$ P.M.: Temperature $104^{\circ}$ pulse 124. Patient passing everything under her, and motions very much relaxed and offensive. -5 P.M.: Temperature $1024^{\circ}$; pulse 124 , weak. Patient now fairly conscious, but much hesitancy in speech and difficulty in finding words; good deal of muttering and trembling of lips. Subcutaneous injection of brandy (ten minims).5.20 P.M. : Temperature $1006^{\circ}$; pulse 128, stronger. Injection of brandy (fifteen minims) subcutaneously. -5.40 P.M.: Temperature $99^{\circ} 6^{\circ}$; pulse weak. The ice was now removed, patient dabbed dry, and put into another bed in the same room between blankets. She was now quiet and conscious.6 P.M.: Temperature $97 \cdot 2^{\circ}$. Injection of brandy (fifteen minims) repeated, and, as patient complained of feeling cold, a hot bottle was applied to the feet.--9.30 P.M.: Temperature $99^{\circ}$. Quite conscious and comfortable.-12 midnight: Temperature $102^{\circ}$; pulse good. Face a little flushed. Ice was applied to the head, and ten grains of sulphate of quinine were given in a little orange juice. The patient was given small quantities of brandy and milk during the night. The temperature taken through the night by patient's sister was as follows: at 1 A.M., $102^{\circ}$; 2 A.M., $103^{\circ}$; 3 A.M., $103^{\circ}$; 4 A.M., $102^{\circ}$; 5 A.M., $103^{\circ}$; 6 A.M., $103^{\circ}$; 7 A.M., $104^{\circ}$. The patient was also given five grains of sulphate of quinine every two hours.

On seeing the patient at 8 A.M. on January 8th, I found she had taken a pint of milk during the night, and about seven dessertspoonfuls of brandy. There had been no sickness. Her temperature was $1033^{\circ}$, and pulse 120 , full and regular; respiration 36 . The patient complained of feeling tired, and seemed inclined to sleep. She had had a fair amount of sleep during the night, and had passed a large quantity of urine naturally, having passed nothing more under her.-11.40 A.M. : Temperature $1018^{\circ}$; pulse 109 ; respiration 33 . Since 8 A.M. has had six dessertspoonfuls of brandy with milk and quinine, five grains every two hours. She is now a little deaf, with some buzzing in ears, and very drowsy. No headache. Last quinine powder was vomited. The brandy and quinine to be discontinued.4 P.M.: Temperature $101 \cdot 6^{\circ}$; pulse 110 ; respiration 37 . The breathing resembles Stokes' respiration. Since 12 o'clock has had no brandy, but has taken a pint of milk without sickness. Quinine (five grains) to be repeated. Ice still to head. The patient expresses herself as much better. The bowels have acted well; motions pale, but not relaxed.9.15 P.M.: Temperature $1015^{\circ}$; pulse 100 ; respiration 36. Has slept a good deal during the day. Takes plenty of milk. The quinine now to be given every four hours. The temperature during the night did not exceed $101.4^{\circ}$.

Jan. 9th.-10.30 A.M.: Temperature $100^{\circ} 8^{\circ}$; pulse 93; respiration 32, more regular and less noisy. Quinine given every six hours. No pain in any of the joints,-9.20 P.M.: Temperature $1004^{\circ}$; pulse 92 ; respiration 32, quiet. This evening the patient says voices have been talking to her. Head has been a little uncomfortable. Since 5 P.M. has had a little pain in the left knee and ankle, also in the wrists, but there is no swelling or redness. Quinine to be discontinued, also ice to be removed from head. Both to be repeated if the temperature reaches $103^{\circ}$

10th.-Breathing normal. No pain anywhere. Temperature through the day varying from $99^{\circ}$ to $100^{\circ}$. The skin has resumed its normal appearance.

11th. - Temperature throughout the day $99^{\circ}$.

12th.-About 11 o'clock last night the pain in the wrists F 2 
returned, and the temperature went up to $101^{\circ}$. This morning the patient has pain in the wrists and shoulders. Ordered ten grains of salicylate of soda every three hours.

13th.-Pain in shoulder still troublesome. Ordered ten grains of salicylate of soda every two hours. Temperature remains about $100^{\circ}$.

16th.-Pain gone from shoulder, which, however, is stiff and powerless. Temperature normal. Shoulder to be well rubbed with oil and worked frequently.

20th.-Temperature still normal. Patient now taking ferri et am. cit., \&c. Shoulder improving.

23rd.-Pationt got up for the first time. Shoulder still stiff. The after treatment consisted in keeping the shoulder well worked, and a mild preparation of iron taken internally.

On March 16th the patient was in her usual health and spirits. All stiffness had disappeared from the shoulder, she had had no return of pain anywhere, and it is satisfactory to state that there had been no cardiac trouble throughout. As in Dr. Taylor's case, the patient remembered nothing afterwards of the cold applications; neither did the temperature again rise to a dangerous height. All temperatures were taken in the axilla, and it was interesting to note as the temperature dropped the gradual transition from violent delirium to consciousness. I think in a subsequent case I should remove the ice and place the patient in blankets earlier than I did in the present one.

Bethune-road, Stamford Hill.

\section{CASE OF ACUTE RHEUMATISM WITH HYPERPYREXIA,}

SUCCESSFULLY TREATED WITH COLD BATHS, AND ICE-BAGS TO THE NAPE OF THE NECK.

BY WALTER GREENE, L.R.C.P., M.R.C.S. LOND.

A. B-, aged thirty-six, came under my care on January 18th, 1887. He was then suffering, he supposed, from the effects of a severe chill, and complained of pain in his limbs and some of his joints, and there was slight fehrile disturbance. When seen three days later the temperature was $103^{\circ}$ and the pulse 120 . There was considerable pain and swelling of the wrists, finger joints, and ankles, and also profuse perspiration, having the characteristic rheumatic odour. I prescribed twenty grains of salicin to be taken every three hours, which was continued for a week, during which time the temperature was fluctuating, but rarely rose higher than $102^{\circ}$, and the joint complications and rheumatic perspirations continued. On the morning of the 28th (Friday) the temperature had risen to $103^{\circ}$, and there was much restlessness. The salicin in twenty-grain doses was then taken every two hours, but in the evening the temperature had risen to $1036^{\circ}$. At 11 o'clock on the following morning (Saturday, January 29th) the temperature was $106^{\circ}$, the pulse 140 and irregular. Shortly after 12 o'clock the temperature had risen to $107.4^{\circ}$; the respirations were 43 ; the pulse was small, irregular, and uncountable; and there was lividity of the face and delirium. I now determined to try the effects of the bath. The only bath available was not long enough to admit of the patient's lying down in it; so he had to be supported in a sitting position, with the water, the temperature of which at first stood at $105^{\circ}$, up to his waist. I then poured cold water over his head, chest, shoulders, and back, from relays of cans and jugs which were kept in constant readiness, so as to afford a continuou supply, the nurse baling the warm water out of the bath as fast as the cold water was poured in. In about twenty minutes the temper ature was brought down to $102^{\circ}$, and his mind appeared to be quite clear. He was then wrapped in a warm blanket and returned into bed. The temperature continued to decline, and in about a quarter of an hour after he had been replaced in bed it had fallen to $104^{\circ}$. A pericardial friction sound was now audible. In the evening the pyrexia was again increasing, and as so much relief had followed the former use of the bath, I determined if necessary to repeat it, and did so when the temperature reached $105^{\circ}$, having first given him an ounce of brandy. As he was very weak, I did not allow him to remain long, but had him wrapped in a warm blanket, and returned to bed as soon as the temperature had fallen to $103^{\circ}$. The bath, as before, was repeated at 3 o'clock in the morning (Sunday, 30th), the temperature having risen to $105^{\circ}$, and again at $11 \mathrm{o}^{\prime} \mathrm{clock}$, the temperature at this time having reached $106^{\circ}$ (the same as on the previous morning at the sume hour). After being replaced in bed, a bag of ice was now kept continually applied to the nape of the neck, and this I found by its occasional removal was exercising a markedly controlling influence upon the temperature, which did net again rise above $104^{\circ}$. The slight pericardial friction sound could still be heard. Towards evening he becamo very restless, and as he bad passed several sleepless nights, I gave him, within half an hour of each other, two doses of thirty minims each of paraldehyde. This having no effect, I then gave him thirty grains of bromide of ammonium, and at the same time a subcutaneous injection of liquor somnifera, after which he had a few short intervals of sleep, lasting about one or two hours at a time. The following morning (Monday, the $31 \mathrm{st}$ ), the temperature being $104^{\circ}$, I gave him twentygrain powders of salicylate of soda every three hours. He took five, but the effect upon the temperature was insignificant. The extreme restlessness, or rather wakefulness, which had continued through the day, increased in the evening, and towards midnight he appeared to be sinking. He was unconscious, though lying apparently awake, with his eyes wide open. The pulse was exceedingly small, and quite uncountable; the respirations shallow, and 44 to the minute. I then injected over a drachm of ether subcutaneously, and gave him an ounce of brandy. A marked improvement in the pulse ensued, and consciousness returned. He was, however, still very restless, so I prescribed forty grains of urethan, which, although it did not induce sleep, seemed to improve the character of the pulse. I then injected three minims of liquor somnifera subcutaneously, and in about a quarter of an hour after this the respirations had fallen to 19 and the pulse to 108 , and he slept quietly for two or three hours. On awakening, some milk was taken, and I again gave him forty grains of urethan, after which the general condition greatly improved, and he slept at intervals the greater part of Tuesday morning. During the following three days, although the patient was very prostrate, the temperature gradually fell, and a slight improvement was observable. There was, however, a tendency to nervous excitement, and I prescribed each night eighty grains of urethan, and injected subcutaneously three minims of liquor somnifera. The pericardial friction sound, first observed on the Sunday, was still audible, little or no liquid effusion having taken place. The pain and swelling of the joints gradually decreased. Each day some progress was made, and on Feb. 4th he was able to sit up, complaining only of great weakness and some stiffness in his joints. On the evening of Feb. 19th he appeared to be threatened with a relapse. His hands, wrists, and shoulder joints became swollen and painful; he was bathed in a profuse perspiration having the rheumatic odour; the temperature rose to $101.2^{\circ}$, and the pulse to 109, and in the night he complained of a sharp pain in the præcordial region. In addition to the quinine which he had been taking in five-grain doses twice daily from the time the temperature subsided, I now gave him twenty-grain doses of citrate of potash. These symptoms continued for about a week, and then gradually passed off, leaving him exceedingly weak and helpless. From this time, however, he slowly and steadily progressed towards recovery. It was a noteworthy feature in this case that when the temperature was rapidly rising; and while the hyperpyrexia continued the joint pains and acid perspirations entirely disappeared. At such times the skin was dry, and the patient seemed to move his limbs freely and without apparent discomfort

Remarks.-This is his third attack of acute rheumatism, and the high temperature coupled with delirium, and the signs of a failing circulation, as indicated by the lividity of the surface and an almost imperceptible pulse, are sufficient to mark it as being one of the greatest severity. It presents points of great practiral interest. Salicin and salicylate of soda failed to exercise their so-called specific action. From January 21 st to $29 \mathrm{th}$ my patient had taken at least 1280 grains of salicin, and in spite of this the temperature had risen to $107^{\circ} 4^{\circ}$. No better result followed the administration of salicylate of soda, of which he took 100 grains, though in both instances the drugs were of excellent quality. The effect of cold baths in these extreme cases is well known and needs no comment, but the influence on the tempera- 